Florida State University College of Law

Scholarship Repository

Scholarly Publications

$12-2013$

\title{
Optimal Warning Strategies: Punishment Ought not to be Inflicted where the Penal Provision is not Properly Conveyed
}

Murat C. Mungan

Florida State University College of Law

Follow this and additional works at: https://ir.law.fsu.edu/articles

Part of the Criminal Law Commons

\section{Recommended Citation}

Murat C. Mungan, Optimal Warning Strategies: Punishment Ought not to be Inflicted where the Penal Provision is not Properly Conveyed, 9 REV. L. \& ECON. 303 (2013),

Available at: https://ir.law.fsu.edu/articles/110

This Article is brought to you for free and open access by Scholarship Repository. It has been accepted for inclusion in Scholarly Publications by an authorized administrator of Scholarship Repository. For more information, please contact efarrell@law.fsu.edu. 


\title{
Murat C. Mungan* \\ Optimal Warning Strategies: Punishment Ought Not to Be Inflicted Where the Penal Provision Is Not Properly Conveyed
}

\begin{abstract}
Law enforcers frequently issue warnings, as opposed to sanctions, when they detect first-time offenders. However, virtually all of the law and economics literature dealing with optimal penalty schemes for repeat offenders suggest that issuing warnings is a sub-optimal practice. Another observed phenomenon is the joint use of warnings and sanctions in law enforcement: person $A$ may receive a sanction, whereas person $B$ is only warned for committing the same offense. This situation can be explained through the use of hybrid warning strategies, a concept not yet formalized in the law enforcement literature, where law enforcers issue warnings to $x \%$ and sanctions to $(100-x) \%$ of first-time offenders. This article uses a two-period optimal deterrence model to provide a rationale as to why it may be optimal to issue warnings. When uninformed individuals are present and their punishment is assumed to be costly, there is a trade-off between such costs and reduced levels of deterrence. Depending on the cost structure associated with the punishment of uninformed individuals, warning strategies, including hybrid ones, may be optimal. A secondary contribution of this article is to point out that lack of information concerning laws may lead to optimal escalating punishments for repeat offenders.
\end{abstract}

Keywords: warnings, law enforcement, repeat offenders, crime and deterrence, optimal sanctions

JEL Classification: K00, K14, K42

*Corresponding author: Murat C. Mungan, Florida State University College of Law, 425 W. Jefferson Street, Tallahassee, FL 32306-1601, USA, E-mail: mmungan@law.fsu.edu

\section{Introduction}

[P]unishment must be inefficacious ... [w] here the penal provision, though established, is not conveyed to the notice of the person on whom it seems intended that it should operate. ... [P]unishment ought not to be inflicted ... [w] here it must be inefficacious. ${ }^{1}$

Jeremy Bentham (1789)

1 Bentham (1789), Chapter 13, section iii. 
More than 200 years ago, Bentham hinted at why sanctions should not be imposed when people are provided with insufficient notice regarding the illegality of criminalized behavior. One way modern law enforcers heed Bentham's suggestion is by the use of warnings. By issuing warnings, law enforcers forgo the opportunity of sanctioning a person who committed an illegal act. However, leaving aside a few exceptions, the existing law and economics literature dealing with optimal penalty schemes for repeat offenders suggests that issuing warnings is a sub-optimal practice. ${ }^{2}$

For high-harm offenses where an overwhelmingly large proportion of society is informed of the illegality of the offense, such as murder and rape, the literature on repeat offenders provides the correct result, which is also consistent with actual enforcement policy: murderers and rapists are not warned. But, for low-harm crimes where a proportion of society may lack information, actual enforcement policy is inconsistent with the implications of most of the existing economic theory. Officers sometimes warn people for illegal U-turns, and administrative officers may warn businesses for violating minor regulations.

In this article, I construct an economic model that provides rationales as to when and why using warnings may be socially desirable and derive the Benthamite conclusion cited above, namely that "punishment ought not to be inflicted" where "the penal provision, though established, is not [properly] conveyed." 3 Specifically, by using an optimal deterrence model - as in Polinsky and Shavell (2007) - I demonstrate that warnings ought to be used more frequently when society has less information concerning the illegality of the criminalized act.

For this purpose, I incorporate hybrid warning strategies, which have not yet been formalized in the literature despite their frequent use. Hybrid warning strategies refer to cases where law enforcers issue warnings $x \%$ of the time and sanctions $(100-x) \%$ of the time. This is consistent with cases where person $A$ receives a sanction for a particular offense, like speeding, where person $B$ is only warned, even though he commits the same act. ${ }^{4}$ To derive the

2 Two exceptions are Emons (2007) and Rousseau (2009) which are discussed later in this section. For models dealing with optimal penalty schemes for repeat offenders see Chu et al. (2000), Emons (2003, 2004), Miceli and Bucci (2005), Mungan (2010, 2012), Polinsky and Shavell (1998), and Polinsky and Rubinfeld (1991). For a general review of the law and economics literature on law enforcement, see Garoupa (1997), Polinsky and Shavell (2000), and Polinsky and Shavell (2007).

3 Bentham (1789), Chapter 13, section iii.

4 Police officers may use discretion in issuing warnings. Section 4.5 contains a few comments regarding the use of discretion, but the theoretical part of this article abstracts from the issue and shows that hybrid warnings can be optimal even at the absence of discretion. For an economic analysis and discussion of the determination of optimal discretion, see Shavell (2007). 
Benthamite conclusion summarized above, I show that the optimal $x$ is (weakly) ${ }^{5}$ decreasing in the number of individuals informed about the illegality of the criminalized act.

I exploit two assumptions to derive this result. First, to incorporate the informative value of warnings, I assume that individuals may be uninformed of the illegality of various acts, and that warnings may provide adequate notice of the relevant laws. ${ }^{6}$ Second, I assume that there are costs associated with the punishment of uninformed individuals. This is an unusual variant of the often employed assumption in the law and economics literature that there are costs associated with the punishment of the innocent. ${ }^{7}$ Therefore, further elaboration on this assumption is warranted.

Existing criminology literature identifies various costs associated with unfair procedures. ${ }^{8}$ In particular, previous empirical studies provide support for the hypothesis that unfair procedures lead to a perception of low legitimacy of authorities, ${ }^{9}$ which is often used as a synonym for lack of trust in government. ${ }^{10}$ Low legitimacy and lack of trust in government, in turn, have been found to be linked to a greater likelihood of participation in strikes, ${ }^{11}$ willingness to engage in

5 The relationship is weak because of corner solutions. More precisely, when the illegality of an act is unknown to a proportion of society exceeding a critical proportion $(\bar{\alpha})$, it is optimal to use pure warnings (i.e. $x=100$ ). Accordingly, for proportions above this threshold, the optimal $x$ is constant at 100. A similar result holds when the proportion of uninformed individuals is below a certain threshold $(\alpha)$, in which case the optimal $x$ is constant at $0 . x$ is strictly increasing in the proportion of uninformed individuals $(\alpha)$ when $\bar{\alpha}>\alpha>\underline{\alpha}$. This result is discussed in further detail in Section 2, infra.

6 Warnings, in general, are meant to give notice to or caution individuals who are presumed to lack information regarding a certain issue. (See Black's Law Dictionary's (8th ed. 2004) definition of warning: 'The pointing out of a danger, esp. to one who would not otherwise be aware of it.')

7 Articles invoking the assumption that there are costs associated with such judicial errors include Stigler (1970), Posner (1973), Png (1986), Miceli (1990), Chu et al. (2000), and Lando (2009). See also Mungan (2011) and Rizzolli and Saraceno (2011), providing utilitarian justifications for the assumption that there are costs associated with the punishment of the innocent.

8 See, e.g. Folger and Konovsky (1989), Konovsky and Cropanzano (1991), and Tyler (1990), studying the negative effects of unfair procedures.

9 Sunshine and Tyler (2003:513), for instance, state that "the key antecedent of legitimacy is the fairness of the procedures used by the police".

10 See, e.g. Tyler (1990:28): "A[n] approach to assessing legitimacy is to measure the extent to which authorities enjoy the public's support, allegiance, and confidence (in political science often subsumed under the heading 'trust in government')".

11 Seligson (1980). 
violent protests, ${ }^{12}$ land invasions, ${ }^{13}$ non-responsiveness to military discipline, ${ }^{14}$ non-compliance with authorities, ${ }^{15}$ and other socially costly behavior. ${ }^{16}$

It is plausible to assume that individuals perceive legal procedures to be 'unfair' when they are punished despite being uninformed about the illegality of their actions. This assumption is supported by the presumption that "the offender defines a criminal sanction as unfair" when he believes that the sanction is undeserved, ${ }^{17}$ and presumably an offender is less likely to feel he deserves a sanction when he lacks knowledge of the illegality of his actions. As such, I will assume that the punishment of uninformed individuals leads to social costs by weakening the social ties between citizens and law enforcers.

When uninformed individuals are present and their punishment is assumed to be costly, issuing warnings can be an optimal practice. Issuing actual fines for first-time offenders has two primary functions: deterrence of informed first-time offenders and informing a fraction of uninformed first-time offenders. However, this comes at the cost of punishing uninformed individuals. On the other hand, warnings only inform a fraction of uninformed first-time offenders and they lack the deterrent function of actual fines; however, they do not generate costs associated with the punishment of the uninformed. Hence, if the cost of punishing uninformed individuals outweighs the benefits from increased deterrence of informed first-time offenders, issuing warnings is an optimal practice. Moreover, in certain cases, it may be possible to employ hybrid warning strategies to balance expected costs associated with the punishment of uninformed individuals and costs associated with under-deterrence.

Results obtained in this article are relevant for designing guidelines for the use of warnings. In particular, the possibility of mitigating losses due to the punishment of uninformed individuals, without resorting to discretion, leads one to believe that the benefits of non-discretionary regimes may be understated. This article also allows a discussion of how warning strategies should evolve as a function of the age of the law. Presumably, the older the law, the more knowledge there is concerning it. Hence, as a law gets older, the necessity of using warnings in its enforcement is reduced. Furthermore, the government

12 See, e.g. Worchel et al. (1974).

13 Seligson (1980).

14 See, e.g. Wesbrook (1980).

15 Tyler (1990:58) finds that "[t]he results of the regressions suggest that legitimacy has a significant independent effect on compliance, even when other potential causal factors are controlled for". See also Sunshine and Tyler (2003).

16 Tyler (1990:34-36) provides a list of studies examining the link between concepts related to legitimacy and socially costly behavior.

17 Sherman (1993:460). 
can influence the amount of information available concerning the illegality of acts through informational campaigns. The more the government expends resources on such campaigns, the more knowledge there will be concerning relevant laws, and the less need there will be for resorting to warnings. As such, the desirability of using warnings depends, among other things, on the relative social cost of such informational campaigns. Also, results presented in this article are consistent with the legal rule that ignorance of the law is not a defense. Indeed, the model assumes this rule: law enforcers are assumed to not ask whether a person is ignorant of the law in question. This assumption reflects the optimal approach whenever there are high costs associated with determining a person's level of knowledge of the law. ${ }^{18}$ This article also contributes to the interpretation of the "puzzle" concerning escalating punishments for repeat offenders. ${ }^{19}$ In particular, as demonstrated in Section 2, non-escalating punishments can be optimal only if the use of hybrid warning strategies is socially desirable. An immediate extension of this result is that when hybrid warning strategies are not used (as is assumed in the existing literature so far), escalating punishments for repeat offenders are always optimal. A last and rather trivial implication that follows from this article is the inefficiency of $e x$ post facto laws. By definition, no individual has knowledge concerning an ex post facto law at the time the offense takes place. Accordingly, there are losses associated with the punishment of uninformed individuals, but no gains associated with increased deterrence. Therefore, ex post facto laws are inefficient.

This article also fills in some gaps in the existing literature. Most articles in the literature dealing with optimal punishment schemes for repeat offenders ${ }^{20}$ ignore costs associated with the punishment of the uninformed. Accordingly, they do not generate results that provide a justification for the use of warnings in law enforcement. On the other hand, some articles suggest that it may be optimal not to sanction first-time offenders. ${ }^{21}$ But, not punishing offenders is not the same thing as warning them. Warnings have an informative function,

18 On which, see Kaplow (1990).

19 Dana (2001) and Emons (2003) refer to the problem of punishing repeat offenders as a puzzle. This is because escalating punishments are observed frequently, but there are many models implying that this is a sub-optimal practice.

20 See note 2, supra.

21 See Harrington (1988), which deviates from the main framework for analyzing optimal punishments for repeat offenders. An implication of this article is that warnings may be optimal. However, this result is not due to the informational function of warnings, but due to the design of a mechanism which allows offenders to move from one group to another where the regulator determines the monitoring rates of each group. Accordingly, Harrington (1988) does not highlight the informational functions of warnings as the instant article does. 
which is not focused on the existing literature. To illustrate how the instant article builds on the existing literature, Emons (2007), Rousseau (2009), and Chu et al. (2000) should be briefly reviewed. The former two because they are examples of models which suggest that under various circumstances first-time offenders should not be punished, and the latter because it incorporates costs associated with the punishment of innocent individuals.

Emons (2007) and Rousseau (2009) conclude that, under certain circumstances, first-time offenders should not be sanctioned. However, these models do not attach an informative function to warnings, and the justification of nonpunishment for first-time offenders relies on wealth constraints in Emons (2007) ${ }^{22}$ and the presence of erroneous measurements in Rousseau (2009). In Chu et al. (2000), the authors incorporate costs associated with the punishment of innocent individuals, but their result is not concerned with warnings. The focus is on whether increasing penalty schemes are better than uniform ones. Furthermore, since the article does not focus on warnings, the authors do not model the informative function of warnings as the instant article does. It is also worth mentioning that none of these articles attempt to model hybrid warning strategies.

Unlike optimal punishments for repeat offenders, the effect of uninformed individuals on law enforcement is infrequently analyzed. Two exceptions are Kaplow (1990) and Friehe (2009). Kaplow (1990) identifies optimal sanctions and deterrence when uninformed individuals are present and conditions under which it is efficient for tribunals to incur costs to differentiate between informed and uninformed individuals. This article also considers individuals who have the option of expending resources to learn about the law. The goal of Kaplow (1990), however, is not to study warnings or the dynamic effects of sanctions (or warnings) in terms of informing people of the illegality of a certain act. As such, it considers a single period model that does not incorporate warnings and, incidentally, does not make observations concerning optimal penalties for repeat offenders. Friehe (2009), on the other hand, extends Kaplow (1990) to a two-period setting and shows that "[e]scalating penalties can be optimal in this setting if the uninformed overestimate the probability that their act is sanctionable." ${ }^{23}$ Accordingly, whereas Friehe (2009) relies on pessimistic beliefs to provide a justification for escalating punishment schemes, this article relies on presumptions of legality, which can be interpreted as optimism, to derive optimal escalating punishment schemes, as well as warnings.

22 Furthermore, this conclusion requires that individuals must be constrained to choose between always committing a crime and never committing a crime, in other words, individuals' strategies are constrained to be history independent.

23 Friehe (2009:167). 
The next section provides a formal model, identifies optimal warning strategies, and investigates the optimality of escalating punishments for repeat offenders. Section 3 discusses a few technical assumptions. Section 4 contains conjectures regarding implications of the model under alternative assumptions, and it discusses policy implications. The Appendix contains proofs for a lemma and various propositions described in Section 2.

\section{The model and analysis}

Society consists of informed and uninformed individuals. Informed individuals are aware that a certain act is illegal and know the expected sanction associated with the commission of that act, whereas uninformed individuals are unaware of the illegality of the same act. $\alpha$ denotes the proportion of uninformed individuals in society. Individuals, regardless of their types, derive benefits (represented by $b$ which is positive and is distributed with density $f(b)$ ) from the commission of this act, which causes an expected harm of $h$ to society. There are two periods. The government possesses a detection mechanism, which catches offenders with a probability of $p,{ }^{24}$ which is assumed to be fixed and interior (i.e. $p \in(0,1)$ ). ${ }^{25} \mathrm{~A}$ policy variable chosen by the government is $q$, the hybrid, pure, or no-warning strategy employed by law enforcers. ${ }^{26}$ When $q=0[q=1]$, all first-time

24 I assume that the government's detection mechanism may generate the error of acquitting guilty individuals, but not the error of convicting innocent individuals. Incorporating such errors, which have been analyzed in the literature, e.g. by Rizzolli and Saraceno (2011) and Mungan (2011), may provide another justification for the use of warnings, because the cost of punishing an innocent individual presumably exceeds the cost of warning him. There is, however, an ongoing debate as to how such errors ought to be incorporated in crime and deterrence models (see, e.g. Garoupa and Rizzolli (2012) and Lando (2006)). I am, therefore, excluding such potential benefits from the social welfare calculus.

25 See Section 4.1., infra, for a discussion of how an endogenous $p$ would interact with optimal warning strategies. See also Mungan (2010:174), arguing for the plausibility of this assumption: "This is a commonly employed assumption in the literature. Polinsky and Rubinfeld (1991), Burnovski and Safra (1994), Chu et al. (2000), Nyborg and Telle (2004), and Miceli and Bucci (2005) are examples of models which impose this assumption. Furthermore, when general enforcement is possible, for low levels of harm, $p$ can be treated as a fixed value although it is endogenously determined. The last point is formalized in Shavell (1991) ...”

26 A pure warning strategy refers to issuing warnings to all first-time offenders. The meaning of the word pure in this context is clearly distinguishable from its meaning in the context of pure strategies in game theory, where the word indicates that a player's likelihood of playing a given strategy is 1. Stated differently, whereas in standard game theory the word pure refers to the likelihood of a given strategy being played, in the present context it refers to the proportion of individuals being warned. 
offenders are warned [sanctioned]. $s_{1}$ and $s_{2}$, respectively, denote the endogenously determined sanction imposed on first-time offenders who are not warned and repeat offenders. A repeat offender is a person who is caught committing a crime in the second period subsequent to being warned or sanctioned in the first period, and a first-time offender is a person without a criminal record who is caught committing a crime. ${ }^{27}$ It is assumed that sanctions are costless to impose and that individuals are not wealth constrained (i.e. judgment proofness is not an issue). ${ }^{28}$

Uninformed individuals are unaware of the illegality of the act and, accordingly, do not expect to be sanctioned. Since they derive benefits from the commission of the act, they commit it. However, once they are warned or sanctioned, they are informed of the law and the illegality of the act. ${ }^{29}$

I assume costs associated with the punishment of the uninformed. Such costs can only be generated through the punishment of first-time offenders, because a person who has a criminal record must have been informed of the illegality of his act through the imposition of a fine or warning for his first offense. Let $\theta$ denote the number of people being punished despite being uninformed, and let $\Psi\left(s_{1}\right)$ denote the cost associated with the punishment of an uninformed individual. Using this notation, total costs associated with the punishment of uninformed individuals is given by $\theta \Psi\left(s_{1}\right)$. In general, $\Psi(0) \geq 0$. This reflects the fact that there may or may not be fixed costs associated with the punishment of uninformed individuals. In Section 2, I focus on the more specific case of $\Psi(0)>0$ and consider the implications of allowing for $\Psi(0)=0$ in Section 3.

27 Therefore, a person whose past crimes have gone unnoticed is considered a first-time offender.

28 When individuals are wealth constrained, as discussed in the literature (see, e.g. Polinsky and Shavell (2007)), it may be optimal to resort to non-monetary and therefore costly means of punishing individuals. The case of costly sanctions is briefly discussed in Section 4.2.

29 Robinson and Darley (2003, 2004) argue that many individuals do not know the exact content of the relevant criminal code. Some of these individuals may nevertheless not commit crime. It may appear that the instant model is at odds with this observation, since uninformed individuals are assumed to commit crime. This assumption is mainly simplifying, and one can consider a more realistic assumption which produces the same results as in this article. In particular, one may consider two types of uninformed individuals. The first commits crime whereas the second refrains from committing crime when uninformed. The latter type of individuals never commit crime and therefore need not be deterred or punished. Therefore, they have no impact on social welfare and can legitimately be left out of the social calculus. As such, one can proceed with the analysis as if the former and simpler assumption were true. 
I assume individuals are risk-neutral expected utility maximizers with nondiscounted additive utility over time. I use the following notation for modeling purposes:

$h>0$; harm generated by the act.

$b>0$; benefit received from the commission of the act.

$f(b)$; density function describing distribution of benefits among individuals. $f(b)$ is positive over $[0, \infty)$.

$p \in(0,1)$; probability of detection.

$q$ with $0 \leq q \leq 1$; hybrid, pure, or no-warning strategy employed by law enforcers, where $q$ and $(1-q)$, respectively, denote the proportion of first-time offenders being sanctioned and warned.

$s_{1}, s_{2} \geq 0$; finite monetary fine extracted from first-time offenders and repeat offenders, respectively.

$\theta(q)$; endogenously determined proportion of society being punished despite being uninformed.

$\Psi\left(s_{1}\right)$; with $\Psi\left(s_{1}\right)=k+C\left(s_{1}\right)$ is the cost of punishing a single uninformed individual and $C^{\prime}>0, C^{\prime \prime} \geq a$ for all $s_{1}$ where both $k$ and $a$ are positive constants. $^{30}$

$I\left(q, s_{1}\right)=\theta(q) \Psi\left(s_{1}\right)$; total costs associated with the punishment of uninformed individuals. These will be called "information costs".

To analyze optimal policy variables, I proceed by backward induction, which requires identifying informed and uninformed individuals' responses to any given set of policies. Then, I derive a utilitarian social welfare function and solve the social planner's problem given individuals' best responses to policy variables.

\subsection{Informed individuals' decision making process}

Informed individuals know that a certain act is a crime, and it is punishable by law. As in Becker (1968), these individuals weigh the benefits against the expected costs from committing a crime. When the second period is reached, an individual only considers second period expected payoffs associated with her

30 In Section 3, I demonstrate the purpose of having $C^{\prime \prime} \geq a$. This is mainly a simplifying assumption for expositional purposes and to ease the description of proofs. A weaker condition which would grant the same simplifying properties is $C^{\prime \prime}(x) \geq \frac{a}{x}$. I also discuss the implications of having $k=0$. 
decisions, which depend on whether she enters the second period as a first-time or repeat offender. An immediate observation follows ${ }^{31}$ :

Observation 1 (i) An informed first-time offender commits crime in the second period iff $b>q p s_{1}$. (ii) A repeat offender commits crime iff $b>p s_{2}$.

These inequalities govern the decisions of all informed individuals in the second period. Individuals foresee their behavior in the second period and know that this behavior will depend on whether or not they are caught in the first period. Hence, their decisions in the first period can be summarized as follows:

Lemma 1 Let $q s_{1}>s_{2}$ (Case I), $q s_{1}=s_{2}$ (Case II), and $q s_{1}<s_{2}$ (Case III) denote all possible cases. Individuals will act in the first period under these three different cases depending on their benefits from crime as follows:

$$
\text { Case I : }\left\{\begin{array}{cc}
\text { don't commit the illegal act } & \text { if } \frac{p}{1+p}\left[q s_{1}+p s_{2}\right] \geq b \\
\text { commit } & \text { otherwise }
\end{array}\right.
$$

$$
\text { Cases II and III : }\left\{\begin{array}{cc}
\text { don't commit the illegal act } & \text { if } q p s_{1} \geq b \\
\text { commit } & \text { otherwise }
\end{array}\right.
$$

Proof: See Appendix.

Lemma 1 and Observation 1, respectively, describe individuals' first and second period best responses to sanctions and warning strategies chosen by the government. These best responses can be summarized by the following:

Observation 2 Let cases I-III denote the same situations as they do in Lemma 1. Informed individuals' behavior as a function of sanctions and warning strategies chosen by the government are given by:

$$
\text { Case I }\left\{\begin{array}{cc}
\text { don't commit the act in either period } & \text { if } b \in\left[0, \frac{p}{1+p}\left[q s_{1}+p s_{2}\right]\right] \\
\text { commit in 1st period and commit in } & \text { if } b \in\left(\frac{p}{1+p}\left[q s_{1}+p s_{2}\right], q p s_{1}\right] \\
\text { 2nd period iff caught in 1st period } & \text { otherwise } \\
\text { commit in both periods } &
\end{array}\right.
$$

31 I assume that indifferent individuals do not commit crime. 
Case II $\left\{\begin{array}{cc}\text { don't commit the act in either period } & \text { if } b \in\left[0, q p s_{1}\right] \\ \text { commit in both periods } & \text { otherwise }\end{array}\right.$

Case III $\left\{\begin{array}{cc}\text { don't commit the act in either period } & \text { if } b \in\left[0, q p s_{1}\right] \\ \text { commit in 1st period and commit in } & \text { if } b \in\left(q p s_{1}, p s_{2}\right] \\ \text { 2nd period iff not caught in 1st period } & \\ \text { commit in both periods } & \text { otherwise }\end{array}\right.$

\subsection{Uninformed individuals' decision making process}

Uninformed individuals, by definition, do not know that a certain act is a crime. However, they are (made aware of its illegality), if they receive a warning or a fine in the first period and become informed individuals in the second period. Since these individuals receive benefits from committing the illegal act and do not perceive an expected cost from engaging in that activity, they commit crime in the first period. ${ }^{32} \mathrm{~A}$ fraction $p$ of these individuals are caught and either sanctioned or warned. These individuals become informed of the illegality of the act and are deterred from committing crime for a second time if the penalty for repeat offenders is sufficiently high. Hence, these individuals' behavior can be summarized by the following observation.

Observation 3 Uninformed individuals' behavior as a function of sanctions and warning strategies chosen by the government are given by:

Cases I, II and III

$\left\{\begin{array}{l}\text { 1st period } \\ \text { 2nd Period commit the act if } p s_{2}<b \text { or if not detected in the first period }\end{array}\right.$

\subsection{Social welfare}

The utilitarian objective of the government is mitigating total net losses arising from non-deterrence and abstaining from punishing uninformed individuals. The latter objective is reflected through a cost function which increases in the number of uninformed individuals being sanctioned and the severity of sanctions imposed on them:

32 This is true even for uninformed individuals whose actual net expected benefits are negative. 


$$
I\left(q, s_{1}\right)=\theta(q) \Psi\left(s_{1}\right)=\theta(q)\left[k+C\left(s_{1}\right)\right]
$$

The first objective is reflected through net aggregate benefits from crime. This is described by:

$$
\int_{O_{1}\left(s_{1}, s_{2}, q\right)}(b-h) f(b) d b+\int_{O_{2}\left(s_{1}, s_{2}, q\right)}(b-h) f(b) d b
$$

where $O_{1}$ and $O_{2}$ denote the set of offenders in the first and second periods, which depend on policy variables chosen by the government and determined via Observations 2 and 3.

Hence, the objective of the government is to maximize:

$$
\int_{O_{1}\left(s_{1}, s_{2}, q\right)}(b-h) f(b) d b+\int_{O_{2}\left(s_{1}, s_{2}, q\right)}(b-h) f(b) d b-\theta(q)\left[k+C\left(s_{1}\right)\right]
$$

Note that $\theta(q)$, the number of uninformed individuals being sanctioned, is a constant multiplied by $q$. To see this, observe that in the first period all uninformed individuals commit crime and $p$ of them are caught. In the second period, $(1-p)$ of them are still uninformed and commit crime, and a $p$ fraction of these individuals are caught. However, only a $q$ proportion of these individuals are sanctioned. Therefore, $q(2-p) p$ is the proportion of uninformed individuals being sanctioned which implies that:

$$
\theta(q)=q(2-p) p \alpha
$$

Hence, eq. (3) becomes

$$
W=\int_{O_{1}\left(s_{1}, s_{2}, q\right)}(b-h) f(b) d b+\int_{O_{2}\left(s_{1}, s_{2}, q\right)}(b-h) f(b) d b-q(2-p) p \alpha\left[k+C\left(s_{1}\right)\right]
$$

\subsection{Optimality}

Maximizing $W$ requires choosing a sanction pair $\left(s_{1}, s_{2}\right)$ and $q$. It should first be noted that information costs, namely $I\left(q, s_{1}\right)=\theta\left[k+C\left(s_{1}\right)\right]$, do not depend on the choice of second period sanctions. Having made this observation, one can determine the optimal sanctions $\left(s_{1}^{*}\right.$ and $\left.s_{2}^{*}\right)$ and the optimal warning strategy $\left(q^{*}\right)$ in two steps. Let $S$ denote the expected sanction for first-time offenders $\left(q p s_{1}\right)$. One can first answer the following question: Given any targeted level of $S$, how can one 
minimize informational costs $\left(I\left(q, s_{1}\right)\right)$ ? The answer to this question will provide us with the policy variables $q$ and $s_{1}$, which minimize informational costs given any $S$. After these are determined as a function of $S$, one can go into the second step of the analysis and find the optimal level of expected sanctions for first-time offenders $\left(S^{*}\right)$ and repeat offenders $\left(p s_{2}^{*}\right)$. Once optimal expected sanctions for first-time and repeat offenders are determined, one can easily determine optimal policy variables $s_{1}^{*}$ and $q^{*}$ by finding the information cost-minimizing $s_{1}$ and $q$ when the targeted expected sanction is $S^{*}$ by using the results obtained in step one. Following this two-step approach, the next sub-section identifies policy variables minimizing informational costs given any level of $S$.

\subsubsection{Information cost minimization}

Informational costs are given by:

$$
I\left(q, s_{1}\right)=\theta(q) \Psi\left(s_{1}\right)=q(2-p) p \alpha\left[k+C\left(s_{1}\right)\right]
$$

The objective in this sub-section is to minimize these costs, given any expected sanction for first-time offenders $\left(S=q p s_{1}\right)$. This problem can conveniently be summarized as:

$$
\min _{q, s_{1}} \theta(q) \Psi\left(s_{1}\right) \text { such that } S=p q s_{1}, s_{1} \geq 0 \text { and } 0 \leq q \leq 1
$$

The following proposition summarizes the solution to this problem.

Proposition 1: There exists $\underline{S}$ such that (i) to achieve an expected first period sanction $S_{h} \geq \underline{S}$, the information cost-minimizing strategy is to impose no warnings $\left(q^{m}=1\right)$ along with a sanction of $s_{1}^{m}=\frac{S_{h}}{p}$. (ii) To achieve an expected first period sanction $S_{l}$ such that $0<S_{l}<\underline{S}$, the information cost-minimizing strategy is to impose a hybrid strategy for warnings $\left(0<q^{m}<1\right)$ along with a sanction of $s_{1}^{m}=\frac{s_{l}}{p q^{m}}$. (iii) To achieve an expected sanction of zero, the information cost-minimizing strategy is pure warnings $\left(q^{m}=0\right)$. In this case, first-time offenders are never sanctioned, and therefore, the particular choice of $s_{1}$ does not affect $I$.

Proof: See Appendix.

Proposition 1 states that if the desired level of expected sanctions for first-time offenders is high, then warnings should not be employed. On the other extreme, if the desired expected sanction is zero, first-time offenders should always be warned. These results are rather intuitive. What is perhaps less intuitive is the 
result concerning hybrid warning strategies; hybrid warning strategies are desirable if intermediate or low expected sanctions are targeted. Although these results lead one to conjecture that $q^{m}$, the information cost-minimizing warning strategy, is increasing in the targeted expected sanction, they do not allow us to reach this conclusion. The next proposition verifies this conjecture and determines the precise relation between the targeted expected sanction and the information cost-minimizing policy variables.

Proposition 2: (i) For all $S<\underline{S}$, the information cost-minimizing warning strategy $\left(q^{m}\right)$ is linearly increasing in $S$, with $q^{m}=\frac{S}{S}$ and (ii) for all positive $S<\underline{S}$, the information cost-minimizing sanction $\left(s_{1}^{m}\right)$ for first-time offenders is a constant.

Proof: See Appendix.

Figures 1 and 2 summarize the results obtained in Propositions 1 and 2.

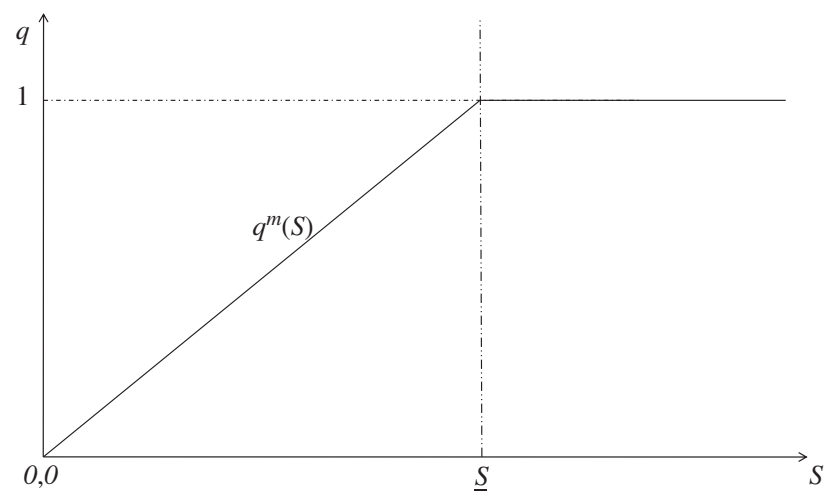

Figure 1: Information cost-minimizing warnings

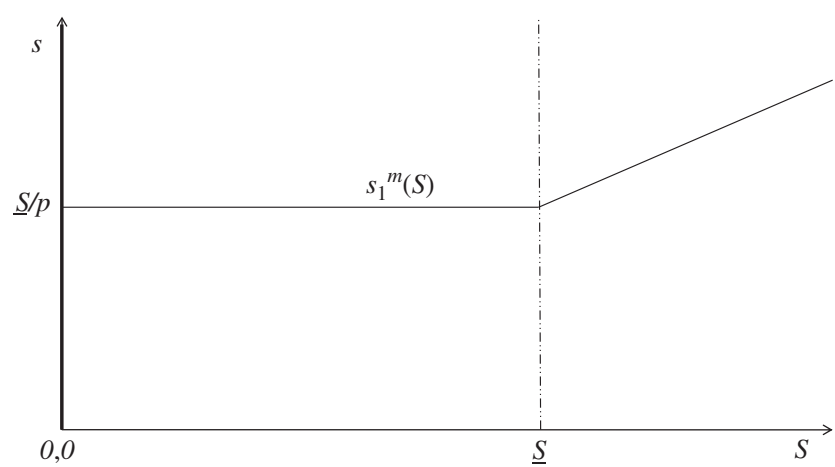

Figure 2: Information cost-minimizing sanctions 
Propositions 1 and 2 provide key results that are frequently exploited in the proceeding parts. Accordingly, it is worth briefly describing the economic intuition behind them. Informational costs are given by $q(2-p) p \alpha\left[k+C\left(s_{1}\right)\right]$. Since $(2-p) p \alpha$ is a constant, we may represent it with a letter, say $A$. Moreover, given the first constraint on the minimization problem, namely $S=q p s_{1}, q$ can be replaced with $S / p s_{1}$ to discuss results. In this case, $A S \frac{k}{p s_{1}}$ and $A S \frac{C\left(s_{1}\right)}{p s_{1}}$, respectively, represent the aggregate fixed and variable costs of punishing uninformed individuals. It is now easy to see that the aggregate fixed cost component $\left(A S \frac{k}{p s_{1}}\right)$ is decreasing in $s_{1}$. This is because aggregate fixed costs only depend on the number of individuals being punished, and greater sanctions allow the targeted expected sanction (i.e. $S$ ) to be met by punishing fewer uninformed individuals. The aggregate variable cost component $\left(A S \frac{C\left(s_{1}\right)}{p s_{1}}\right)$, on the other hand, is increasing in $s_{1}$. This is because the convexity of $C\left(\right.$.) guarantees that the per person information cost (i.e. $C\left(s_{1}\right)$ ) is increasing faster than the number of punished uninformed individuals decreases (i.e. $\left.\frac{A S}{p s_{1}}\right)$. As such, there is a cost component that is increasing in and another one that is decreasing in $s_{1}$. Thus, the information cost-minimizing $s_{1}$ equates the marginal aggregate fixed cost to the marginal aggregate variable cost. This occurs at some $\hat{s}_{1}$, which does not depend on $A$ or $S$, since both of these values scale marginal variable and marginal fixed costs by the same number. $q$, on the other hand, is chosen such that $q=\frac{S}{p \hat{s}_{1}}$.

This simple analysis, however, ignores the second constraint, namely, $0 \leq q \leq 1$. If the targeted expected sanction is very large and $s=\hat{s}_{1}$, then even when warnings are never used (i.e. $q=1$ ) the targeted expected sanction of $S$ cannot be achieved. In these cases, $s_{1}$ cannot be chosen to equate marginal aggregate fixed and variable costs of punishing uninformed individuals. In particular, $s_{1}$ must exceed $\hat{s}_{1}$, and the marginal aggregate variable cost must exceed the marginal aggregate fixed cost of punishing uninformed individuals. In such cases, it is cost-minimizing to go for the solution that minimizes the difference between these two marginal costs. This occurs when $s_{1}$ is chosen as small as possible, which occurs when $q=1$ and $s_{1}=\frac{s}{p}$.

Due to these reasons, as stated in Proposition 2, when the targeted expected sanction is small, $s_{1}$ is chosen at its ideal level of $\hat{s}_{1}$, and $q$ is chosen to make sure the targeted level of expected sanction is met. If, however, the targeted expected sanction is too large, it is not possible to set $s_{1}=\hat{s}_{1}$, since one cannot simultaneously achieve the targeted expected sanction of $S$ and have $q \leq 1$. In these cases, it is optimal to set $q=1$ and $s_{1}=\frac{s}{p}$ to minimize the difference between the marginal aggregate variable cost and the marginal aggregate fixed cost of punishing uninformed individuals. 


\subsubsection{Optimal policy variables}

To determine optimal policy variables, the optimal expected sanction for firsttime offenders must be determined. In turn, this will allow the identification of optimal warning strategies and sanctions for first-time offenders. However, there is a third policy variable that must be chosen, namely $s_{2}$, the sanction for repeat offenders. But, since $s_{2}$ does not affect information costs, its determination is relatively straightforward. The next proposition identifies the optimal sanction for repeat offenders and a range for optimal expected sanctions for first-time offenders. $^{33}$

Proposition 3: The optimal sanction and warning strategy result in under-deterrence for first-time offenders and first-best deterrence for repeat offenders. This is achieved by a sanction pair $\left(s_{1}^{*}, s_{2}^{*}\right)$ and warning strategy $q^{*}$ such that $s_{1}^{*}<\frac{h}{q^{*} p}$ and $s_{2}^{*}=\frac{h}{p}$.

\section{Proof: See Appendix.}

Proposition 3 verifies a claim extended in Section 1: the expected punishment for first-time offenders must be chosen to balance costs associated with underdeterrence and the punishment of uninformed individuals, whereas the expected punishment for repeat offenders must be chosen to induce first-best deterrence. This follows from the fact that all repeat offenders are informed individuals, but there are some first-time offenders who are uninformed. Accordingly, high expected sanctions for first-time offenders generate costs associated with the punishment of uninformed individuals, but the same is not true for expected sanctions for repeat offenders. The following corollary highlights this result.

Corollary 1: Increasing expected sanctions for repeat offenders are optimal (i.e. $s_{1}^{*} q^{*} p<s_{2}^{*} p$ ).

There is a broad literature on the optimal punishment for repeat offenders. ${ }^{34}$ The main debate is centered on the economic rationale as to why repeat offenders should be punished more severely. Corollary 1 points out that under the

33 This proposition assumes $\alpha>0$. When $\alpha=0$, the optimal first period sanctions and warning strategies are such that $s_{1}^{*}=\frac{h}{q^{*} p}$.

34 See note 2, supra. 
assumptions of this model, it is always optimal to subject repeat offenders to higher expected sanctions. The optimality of increasing actual sanctions ( $s_{1}^{*}$ and $s_{2}^{*}$ ) depends on what type of warning strategies are optimal and the harm associated with the offense. Therefore, the identification of conditions for optimal increasing sanctions is delayed until after the determination of optimal warning strategies.

To proceed, note that since $s_{2}^{*}$ is pinned down (by Proposition 3) and the information cost minimization problem is solved (by Propositions 1 and 2), one can easily express the maximum value for social welfare, denoted as $V$, as a function only of the expected sanction for first-time offenders:

$$
V(S)=K+(2-p)(1-\alpha) \int_{S}^{h}(b-h) f(b) d b-I^{*}(S)
$$

where $I^{*}(S)$ denotes informational costs evaluated when $q$ and $s_{1}$ are chosen to minimize such costs and $K$ is simply a constant term capturing benefits/losses of crimes committed by uninformed individuals and repeat offenders. ${ }^{35}$ In the remaining parts of the article, it will be assumed that $V$ is concave in $S$. All that remains is the maximization of $V$ with respect to expected sanctions for first-time offenders. Once this is accomplished, optimal warning strategies can be determined by making use of Propositions 1 and 2. The next proposition summarizes results obtained once these steps are followed. ${ }^{36}$

Proposition 4: (i) The optimal expected sanction for first-time offenders is given by:

$$
\begin{array}{ll}
S^{*}=0 & \text { if } h \leq \frac{\frac{\alpha p}{\underline{S}}\left(k+C\left(\frac{S}{\bar{p}}\right)\right)}{(1-\alpha) f(0)} \equiv h^{\prime}(\alpha) \\
(1-\alpha)\left(h-S^{*}\right) f\left(S^{*}\right)=p \alpha \underline{\frac{1}{S}}\left(k+C\left(\frac{S}{\bar{p}}\right)\right) & \text { if } h^{\prime}(\alpha) \equiv \frac{\frac{\alpha p}{\underline{S}}\left(k+C\left(\frac{S}{\bar{p}}\right)\right)}{(1-\alpha) \dot{f}(0)}<h<\underline{S}+\frac{\frac{\alpha p}{\underline{S}}\left(k+C\left(\frac{S}{\bar{p}}\right)\right)}{(1-\alpha) f(\underline{S})} \equiv h^{\prime \prime}(\alpha) \\
(1-\alpha)\left(h-S^{*}\right) f\left(S^{*}\right)=\alpha C^{\prime}\left(\frac{S}{p}\right) & \text { if } h^{\prime \prime}(\alpha) \equiv \underline{S}+\frac{\frac{\alpha p}{S}\left(k+C\left(\frac{S}{\bar{p}}\right)\right)}{(1-\alpha) f(\underline{S})} \leq h
\end{array}
$$

(ii) For all $\alpha$, (1) for crimes resulting in harm $h \leq h^{\prime}$ the optimal warning strategy is pure warnings $\left(q^{*}=0\right)$, (2) for crimes resulting in harm $h$ with $h^{\prime}<h<h^{\prime \prime}$ the optimal warning strategy is hybrid warnings $\left(0<q^{*}<1\right)$, where

35 For the explicit expression for $K$ and a brief explanation of the derivation of $V(S)$, see the proof of Proposition 3 in the Appendix.

36 This proposition reports results when $\alpha>0$. When $\alpha=0$ any warning strategy accompanied by proper sanctions for first-time offenders is optimal. However, for expositional convenience, critical values $h^{\prime}$ and $h^{\prime \prime}$ in Proposition 4 and Figure 3 are reported as functions with domain $[0,1]$. 
$q^{*}$ is increasing in $\mathrm{h}$, and (3) for crimes resulting in harm $h \geq h^{\prime \prime}$ the optimal warning strategy is no-warning $\left(q^{*}=1\right)$. (4) $h^{\prime}(\alpha)$ and $h^{\prime \prime}(\alpha)$ are both convex and increasing in $\alpha$, approach infinity as $\alpha$ approaches 1 , and $h^{\prime}(0)=0$ and $h^{\prime \prime}(0)=\underline{S}$.

Proof: See Appendix.

As described in Proposition 4, the optimal warning strategy is a function of the proportion of uninformed individuals and the harm associated with crime. Using this proposition, one can plot the optimal warning strategies in $h-\alpha$ space, as is shown in Figure 3.

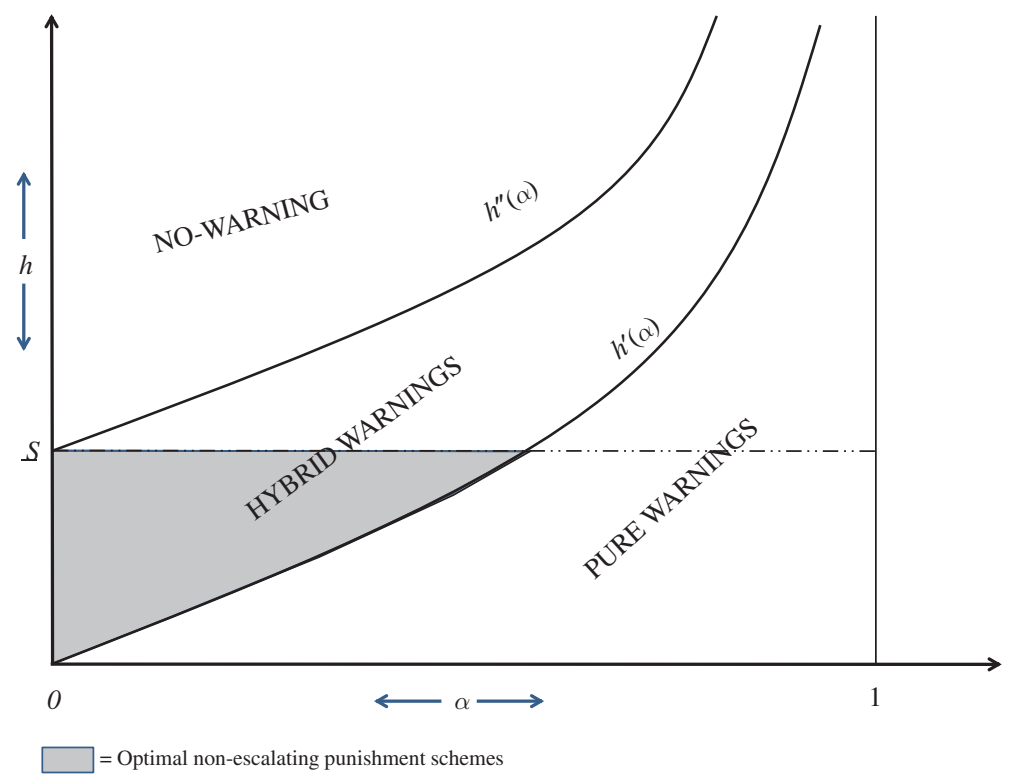

Figure 3: Optimal warning strategies as a function of harm and proportion of uninformed individuals

Further interpretation of Proposition 4 and Figure 3 is provided in Section 4. However, an implication of Propositions 3 and 4 related to the optimal punishment of repeat offenders can be summarized by the following result.

Proposition 5: Escalating penalties for repeat offenders are optimal (i.e. $s_{2}^{*}>s_{1}^{*}$ ), unless (i) the harm associated with the offense is sufficiently low (i.e. $h \leq S$ ) and (ii) hybrid warning strategies are optimal $\left(0<q^{*}<1\right)$.

Proof: See Appendix. 
Proposition 5 contributes to the interpretation of the escalating punishments puzzle $^{37}$ by identifying conditions (highlighted in Figure 3) under which this practice is optimal. It states that escalating punishments are usually optimal and that a necessary condition for their non-optimality is the possibility of imposing hybrid warning strategies. This leads to the conjecture that in standard settings, where some individuals are uninformed and warnings are not possible, increasing punishments for repeat offenders are always optimal. In other words, if the current model was constrained such that $q=1$ always holds, escalating punishments would always be optimal.

\section{Discussion of assumptions}

\subsection{Multiplicative structure}

The multiplicative nature of the information cost function is a product of utilitarianism. $I=\theta[k+C]$ simply states that costs are equal to the sum of per individual costs times the number of individuals incurring or producing such costs. Accordingly, I believe that this particular form is justifiable on utilitarian grounds. The more problematic assumptions are associated with the specific functional form of $C$ and there being fixed costs associated with the sanctioning of uninformed individuals.

\section{$3.2 k>0$}

This assumption simply states that once individuals are punished despite being uninformed, costs are incurred, which are independent of the severity of the punishment. This can be related to the creation of distrust among individuals toward the legal system or simply a feeling of being wronged which may trigger an adverse feeling toward law enforcement in general. Such costs have been identified in the criminology literature and are discussed to some extent in Section 1.

It may be argued that in the special case where $s_{1}=0$ and $q>0$, the functional form makes no sense. In this case, some individuals are not warned, but not sanctioned either (since $s_{1}=0$ ). I will not discuss whether 0-sanctions can trigger a feeling of being wronged or whether they would create distrust.

37 See note 19, supra. 
I will instead point out the fact that in this model, this case is never observed in the optimal solution, hence, the question of whether there should be costs in this special case is moot.

If one believes that 0 -sanctions do not create costs, an alternative reaction might be to alter the structure of informational costs so that $I\left(q, s_{1}\right)=0$ whenever $q=0$ or $s_{1}=0$. This would not alter any of the main results. To see this, note that the proposed alteration on information costs has no effect on costs when both $s_{1}$ and $q$ are positive. Hence, the alteration has no effect on information cost-minimizing strategies when the targeted $S$ is positive, because this requires that $s_{1}>0$ and $q>0$. This implies that $I^{*}(S)$, and therefore $V(S)$, remains the same when $S>0$. Next, note that when the targeted $S$ is zero, the alteration implies that information costs are minimized when $q=0$ or $s_{1}=0$, in which case $I=0$, as in the model in Section 2. Hence, $V(S)$ is unaffected by the proposed alteration on $I\left(q, s_{1}\right)$ and is therefore maximized by the same choices of $S$. This implies that optimal warning strategies and sanctions are unaffected by the alteration when $h>h^{\prime}$. The optimal strategy when $h \leq h^{\prime}$, however, is to have either $q=0$ or $s_{1}=0$ as opposed to $q=0$. Hence, the only effect of the alteration is that when $h \leq h^{\prime}$, it is optimal not only to use pure warning strategies, but also to use zero-sanctions for first-time offenders.

Having identified the reasons as to why I think this assumption is justifiable, I will comment on what the model implies when $k=0$. When $k=0$, information costs are minimized whenever $q=1$, because informational costs are always decreasing in $q$ (see proof of Proposition 1 and set $k=0$ ). Hence, no-warning would always be optimal. From a positive stand point, the inconsistency of this result with what is observed in reality is perhaps another reason as to why $k>0$ is a plausible assumption.

\section{$3.3 C^{\prime \prime} \geq a>0$}

This assumption basically states that costs are always accelerating with the severity of punishment, at or above a certain rate. Admittedly, it is not an intuitive assumption. I would note, however, that this is not a necessary condition. It is rather a sufficient condition which is used to ease the exposition and derivation of results. The purpose of this assumption is to guarantee the existence of the critical expected sanction $(\underline{S})$ which is referred to in a few propositions. In the model's current form, for any $S>\underline{S}$, variable costs $\left(q C\left(\frac{S}{p q}\right)\right)$ decrease faster than fixed costs $(k q)$ increase, in response to an increase in $q$, regardless of the choice of $q$. Hence, for such $S$, it is optimal to choose $q=1$, which minimizes 
$C$ but maximizes $k q$. I believe that it is plausible to assume that such a critical level exists. Otherwise, it would follow that no-warnings can never be optimal even in cases such as murder, where presumably most individuals are informed of the law.

A weaker sufficient condition would be $C^{\prime \prime}(x) \geq \frac{a}{x}$ for some positive $a$. However, this assumption is no more intuitive than the assumption used and requires slightly more complicated notation.

\section{Further discussion}

Next, I discuss several issues which are frequently discussed in the law enforcement literature, including the exogeneity versus endogeneity of the probability of detection $(p),{ }^{38}$ costly sanctions, ${ }^{39}$ the use of discretion, ${ }^{40}$ and escalating punishment schemes. ${ }^{41}$ I also provide some empirical motivation for the theory presented by discussing warnings in the context of real-world observations and how the use of warnings may evolve over time.

\subsection{Interaction between warnings and the probability of detection}

In Section 2, I assumed that the probability of detection $(p)$ is exogenously determined. As such, the model presented does not capture potential interactions between $p$ and $q$. One may, therefore, object to the main findings by reasoning that the exogeneity of $p$ drives results. This criticism may take the following form. Optimality conditions suggest that law enforcers catch individuals committing an offense and release $\left(1-q^{*}\right)$ proportion of first-time offenders committing that offense. This, or a similar result, can be achieved by decreasing the probability of detection $(p)$. Decreasing $p$ is equivalent to punishing fewer uninformed individuals, which is the main function of warnings. In other words, we are using too big of a net to catch fish and are subsequently

38 See, e.g. Polinsky and Shavell (2007:413-414) showing that in the simple law enforcement model under-deterrence is optimal when $p$ is endogenous, whereas it is not when $p$ is exogenous.

39 See, e.g. Polinsky and Shavell (2007, sections 4-9).

40 See, e.g. Shavell (2007).

41 See note 2, supra. 
releasing some of the fish caught. We can instead start with a smaller net. When $p$ is fixed, this possibility cannot be captured by the model, and one cannot confidently claim that warnings are optimal (even if they appear to be optimal in the instant model).

This criticism is best addressed by considering the functional differences between the two policy tools in question (i.e. warnings and the probability of detection). Decreasing the probability of detection $(p)$ as well as increasing the proportion of individuals being warned $(1-q)$ reduces deterrence. Reducing $p$ leads to a lower threat of punishment for first-time offenders as well as repeat offenders, whereas decreasing $q$ has an adverse effect on the deterrence of firsttime offenders only. More importantly, $p$ affects the number of informed individuals in future periods, but $q$ does not. When $p$ is increased, more uninformed individuals are sanctioned or warned in the first period, which converts them into informed individuals in the second period. Warnings, on the other hand, do not produce a similar effect, since information can be disseminated through sanctions as well as warnings. As such, an increase in the rate of warnings is superior to a reduction in the probability of detection as a tool for decreasing the number of uninformed individuals being punished.

This idea can be formalized relatively simply by considering the direct welfare effects of the probability of detection and the proportion of individuals being warned. To do this, I initially assume away enforcement costs (i.e. the physical cost of increasing $p$ as described, for instance, in Polinsky and Shavell (2000)) and focus on costs of punishing uninformed individuals and costs of under-deterrence. As eq. (8) and the proof of Proposition 3 suggest, social welfare can be expressed as:

$$
\begin{aligned}
V(S)= & (1-\alpha)\left[2 \int_{h}^{\infty}(b-h) f(b) d b+(2-p) \int_{S}^{h}(b-h) f(b) d b\right] \\
& +\alpha\left[2 \int_{h}^{\infty}(b-h) f(b) d b+(2-p) \int_{0}^{h}(b-h) f(b) d b\right]-(2-p) p q \alpha\left[k+C\left(s_{1}\right)\right]
\end{aligned}
$$

and recall that $S=p s_{1} q$.

Given any $p^{l}<1$, let the optimal policy choices (as derived in the previous sections) be denoted by $s_{1}^{*}, s_{2}^{*}$, and $q^{*}$. Now consider increasing the probability of detection from $p^{l}$ to $p^{h}>p^{l}$ and decreasing $q^{*}$ to $\frac{p^{l}}{p^{h}} q^{*}$. This change results in an increase in the first term in eq. (9), since the change leaves $S$ unaffected and leads to a reduction in $(2-p)$, the measure of informed individuals being undeterred. A similar positive effect associated with the number of under-deterred and (initially) 
uninformed individuals is captured through the second term. Furthermore, since the change preserves $p q$ and $s_{1}^{*}$, the aggregate cost of punishing uninformed individuals (captured through the third term in eq. (9)) is also reduced.

This simple observation shows that an increase in $p$ necessarily leads to welfare increases. As such, absent enforcement costs, it would be optimal to have a probability of detection of 1 and a high rate of warnings. In other words, if big nets did not cost anything, we would prefer to have the biggest one possible. When there are enforcement costs, the optimal $p$ will depend on the trade-off between these identified costs and benefits and the specific functional form of each. The existence of enforcement costs, however, should not alter the conclusion that a reduction in the probability of detection and an increase in the rate of warnings are not functional equivalents and that the optimality of warnings is not a simple product of assuming an exogenous probability of detection.

\subsection{Costly sanctions}

The model presented in Section 2 assumes that it is costless to impose sanctions. This assumption, as discussed in the existing literature, ${ }^{42}$ is less problematic when monetary sanctions can be used to generate a sufficient threat of punishment. When monetary sanctions are inadequate to deter undesirable conduct, more costly modes of punishment, such as imprisonment, may become necessary. An intuitive conjecture can be made regarding the likely effects of incorporating imprisonment into the model presented in Section 2. Major deviations from results presented in Section 2 are unexpected when imprisonment is required to deter high-harm crimes and imprisonment costs rise proportionally with the expected non-monetary sanction (i.e. $S=q p s_{1}$ ).

To see this, note that, as can be seen from eq. (8), increasing $S$ leads to benefits by reducing under-deterrence and costs by increasing informational costs. When imprisonment costs are present, a third component of welfare emerges that consists of costs increasing in $S$. This implies that the larger imprisonment costs are in relation to gains from deterrence, the lower $S$ that ought to be chosen. As such, the presence of imprisonment costs implies that, ceteris paribus, smaller $S$ 's be chosen. Next, it should be noted that the optimal $q-s_{1}$ pair as a function of $S$ is not altered by the incorporation of imprisonment costs. This follows, because imprisonment costs are assumed to be a function of $S$ (i.e. the product of $q$ and $s_{1}$ ) and do not depend on the specific $q-s_{1}$ pairs

42 See, e.g. Polinsky and Shavell (1984). 
which generate the same $S$ (i.e. imprisonment costs are the same for all $q$ and $s_{1}$ such that $p q s_{1}=S$ ). Therefore, the inclusion of imprisonment costs only affects the optimal $S$, but does not affect the cost-minimizing $q-s_{1}$ pair given the targeted $S$.

These observations imply that the incorporation of imprisonment costs is not expected to significantly alter results, but it is likely to lead to some quantitative changes. In particular, for any given $h$ and $\alpha$, the inclusion of imprisonment costs is likely to push the optimal $S$ downward. As such, $h^{\prime}$ and $h^{\prime \prime}$, as plotted in Figure 3, are likely to shift toward the northwest direction. But since the cost-minimizing $q-s_{1}$ pairs given optimal $S$ 's are unaltered, no-warning strategies remain optimal to the north of the shifted $h^{\prime \prime}$ curve, hybrid warnings remain optimal between the shifted $h^{\prime}$ and $h^{\prime \prime}$ curves, and pure warnings remain optimal to the south of the shifted $h^{\prime}$ curve. This implies that pure warnings and hybrid warnings ought to be used more often compared to the case where imprisonment costs are absent.

\subsection{Consistency of results}

Figure 3 describes optimal warning strategies as a function of the proportion of informed individuals and the level of harm associated with the offense. One can assign certain offenses on this graph to see whether results obtained are consistent with warning strategies employed by law enforcers in reality.

Assigning extreme offenses, such as murder, on the graph is relatively easy. Almost all individuals are informed of the illegality of the crime and harms associated with the crime are very high. Hence, murder would go on the northwest portion of the graph. This suggests that the optimal warning strategy is nowarning, which is consistent with the warning strategies employed in reality.

On the other hand, making an illegal U-turn or illegally switching lanes are associated with lower levels of expected harm. Assuming that expected harms from these offenses fall below the threshold level of $\underline{S}$ is sufficient to suggest that some type of warnings (pure or hybrid) should be employed for these offenses. Furthermore, in certain cases (e.g. when signs are not posted properly or the lanes are not drawn properly), the proportion of individuals who are informed of the law may also be quite low. This implies that these offenses go into the southeast corner of the graph, which suggests pure warnings are optimal.

For intermediate offenses, such as speeding and reckless driving, the optimal warning strategy may depend on the severity of the offense. For instance, driving 100 m.p.h. in a residential area is presumably associated with high expected harms, and most individuals are likely to guess that such an act is 
illegal. In this case, it will be optimal to employ a no-warning strategy. On the other hand, on a country road between two states, individuals may lack information about the speed limits and may have different presumptions. In this case, if the harm associated with this act is sufficiently small, hybrid strategies might be optimal.

There are interesting examples of low-harm/low-information offenses (southeast corner of the graph), which have been enforced through (informal) warnings. Disposing of cigarette butts on streets have been recently illegalized in Turkey, and this act was declared to be a sanctionable offense. The law, however, was not publicized very successfully and was contrary to people's expectations. Law enforcers commonly resorted to informal warnings until citizens became aware of the illegality of disposing cigarette butts.

A separate and rather trivial implication of the model is that ex post facto laws should never be passed. The proportion of individuals, who have knowledge of an ex post facto law, at the time of the commission of the offense, is by definition 0 . This implies that $\alpha=1$, which suggests that no individual should be sanctioned.

Overall, results presented appear to be consistent with warning strategies employed in reality. If there are offenses which are outliers, it may be an interesting task to see if these offenses have some rare properties which are not captured in this article. One can then study these properties which may allow us to make observations concerning their impact on social welfare.

Consistency of results with actual warning practices for well-known offenses (murder, rape, speeding, and other traffic violations) suggests that we, as a society, may in fact be maximizing an objective function which is similar to that suggested in this article. More specifically, we may have a shared intuition that it is costly to punish uninformed individuals and that these costs have the properties described in the preceding parts: there is a fixed cost to punishing an uninformed individual, and such costs are increasing at an increasing rate.

\subsection{Policy implications in a dynamic setting}

Although the model considers two periods, it is static in the sense that it does not consider changes in parameters, such as $\alpha$, over time. Accordingly, it abstracts from issues such as the level of information varying across time and policies. Nevertheless, results obtained through this static model allow us to draw inferences regarding the effects of various policies in a more dynamic setting. 
Presumably, the level of information in society will be low for laws which have been recently passed. Accordingly, one can think of new laws as being associated with a high level of $\alpha$. As time goes by, and the law gets older, a higher proportion of society familiarizes itself with the law due to information dissemination. Hence, the proportion of uninformed individuals $(\alpha)$ decreases as the law ages. This observation leads to the conjecture that, ceteris paribus, newly introduced laws should make use of warnings often; in other words, they ought to be enforced via low- $q$ warning strategies. And as time goes by, and $\alpha$ decreases, warnings should be relied on less heavily. That is to say, law enforcers should move from low- $q$ warning strategies to high- $q$ warning strategies as the law gets older.

There can, however, be exceptions. Consider the case where a technological advance makes it possible for individuals to engage in highly harmful conduct, which is not yet illegal (in this regard, one can consider the use of internet for copyright infringement purposes). The policy recommendation of the instant model would be passing a law illegalizing such conduct and enforcing it without resorting to warnings at all or use high- $q$ warning strategies (in this regard, one can consider the Digital Millennium Copyright Act being implemented strictly).

A simple corollary is observed when the availability of informational campaigns is considered. Politicians and legislators can reduce $\alpha$, the proportion of uninformed individuals, through informational campaigns via social media (e.g. through ads on TV, billboards and online social platforms such as Facebook, and warning trailers on DVDs ${ }^{43}$ ). Although $\alpha$ is assumed to be exogenous in the main sections of this article, the consequences and optimality of such campaigns can be studied by extending the model presented earlier.

It is optimal to rely on warnings less often when informational campaigns are used more often, because such campaigns reduce the proportion of uninformed individuals, and therefore, the marginal benefit from using warnings. ${ }^{44}$ But, whether or not it is desirable to use informational campaigns in the first place depends completely on the relative cost of such campaigns. If the marginal cost of decreasing $\alpha$ through informational campaigns is high in comparison to the increase in social welfare due to a lower proportion of uninformed individuals in society, then it is optimal to not use informational campaigns.

43 Consider, for instance, the following language, which is often used by the FBI to inform people of the consequences of copyright infringements: "The unauthorized reproduction or distribution of this copyrighted work is illegal. Criminal copyright infringement, including infringement without monetary gain, is investigated by the FBI and is punishable by up to 5 years in federal prison and a fine of $\$ 250,000$."

44 This is a direct implication of Proposition 4, which suggests that the optimal $q$ is weakly decreasing in $\alpha$. 
To formalize this point, let $u$ denote informational campaign expenses. Then, $\alpha=\alpha(u)$ and $\alpha^{\prime}<0$. The maximum value of social welfare can now be expressed as:

$$
Z(u)=\max _{S} V(S, \alpha(u))-u \equiv Y(\alpha(u))-u
$$

where $V$ is as defined in eq. (8). If $Y^{\prime} \alpha^{\prime}<1$, then it is optimal to not have informational campaigns. Otherwise, incurring some informational campaign expenses is optimal, and the optimal $u$ depends on the trade-off between direct campaign costs and the marginal increase in $\max _{S} V(S, \alpha(u))$ due to an increase in $u$.

\subsection{Discretion}

Police officers often use discretion in issuing warnings as opposed to sanctions. There may be problems associated with giving police officers discretion, such as increased opportunities for framing and bribery. Presumably, when police officers are acting honestly, on average they make correct rather than wrong guesses in determining whether or not an offender was informed of the law. Hence, as long as there are some potentially corruptible police officers, there are costs and benefits associated with the use of discretion by police officers, and without further investigation it is not clear whether police discretion should be allowed. ${ }^{45}$

This article derives optimal warning strategies, at the absence of discretionary behavior. But the implications of the model can aid in determining optimal discretion policies in two ways. First, implementing hybrid warning strategies, without resorting to discretion, increases the benefits associated with a nodiscretion regime. In a regular law enforcement framework, one would consider the non-discretionary framework as consisting of no-warning or pure warning regimes. However, hybrid warning strategies can be implemented without resorting to discretion. ${ }^{46}$ This increases the maximum welfare achievable in a non-discretionary regime, since the use of hybrid warnings is optimal for crimes with $h \in\left(h^{\prime}, h^{\prime \prime}\right)$. As such, there may be instances in which a non-discretionary regime dominates all discretionary regimes when the availability of hybrid

45 See Shavell (2007), for an extensive analysis as to when and how discretion should be allowed.

46 For instance by requiring police officers to issue warnings $x \%$ of the time and in a particular order. 
warnings is considered, but is dominated by a discretionary regime when only no-warning and pure warning strategies are considered.

Second, welfare can be increased by providing police officers with instructions to issue warnings a certain proportion of the time when they are not confident about their assessments concerning the suspects' guilt. If a police officer cares only about his self-interest, such guidelines will not affect his behavior; he will simply do what is in his best interest. However, when he is acting honestly, there will be cases in which he is not confident about his guess regarding the innocence of an individual. In these cases, discretionary behavior can be supplemented by the use of warnings as suggested in this article, which should lead to an increase in social welfare.

\subsection{Escalating punishment schemes}

Determining how repeat offenders ought to be punished has been regarded as a puzzling task in the existing literature. ${ }^{47}$ This is mainly because many models ${ }^{48}$ imply results that are contrary to our intuition that repeat offenders ought to be punished more severely. Although the instant article was mainly concerned with optimal warning strategies in law enforcement, it also contributes to the literature on the optimal punishment for repeat offenders in several ways.

In general, my results overlap with the intuitive conjecture that repeat offenders ought to be punished more severely. These results are summarized by corollary 1 and Proposition 5 and are briefly interpreted in Section 4. The driving assumption behind these results is that there are uninformed individuals, and their punishment is costly. Repeat offenders are by definition informed individuals, since they were informed of the act's illegality when they were previously caught. On the other hand, a proportion of first-time offenders are uninformed individuals. Hence, repeat offenders can be subjected to sanctions which result in first-best deterrence. On the contrary, such punishments would be undesirably high for first-time offenders due to costs associated with the punishment of uninformed individuals. Therefore, under many conditions, escalating punishments are optimal.

This observation demonstrates one of the reasons as to why we may be confronted with a puzzle in the repeat offender literature. We are abstracting

47 See note 19, supra.

48 Emons (2003, 2004, 2007) are examples of such models. 
from issues related to lack of knowledge concerning laws and the existence of mistakes. ${ }^{49}$ This leads to a second implication, which is related to the optimal increase in the punishment of repeat offenders. If lack of information is (at least partially) responsible for escalating punishments for repeat offenders, then the increase in punishment should be related to how little information there is concerning a law. In particular, ceteris paribus, the more uninformed individuals in society, the greater the increase in the punishment for repeat offenders should be.

In sum, incorporating informational problems in repeat offender models will likely produce results that are consistent with our intuition that repeat offenders should be punished more severely. Furthermore, such inclusion is likely to provide general guidelines as to how punishments for repeat offenders should be increased.

\section{Concluding remarks}

This article attempts to provide a simple framework that allows the incorporation of the informative function of warnings. It captures the trade-off between costs of punishing uninformed individuals and reduced levels of deterrence and identifies sufficient conditions under which using warnings is optimal. Assuming these sufficient conditions hold, it discusses issues related to the use of discretion, evolution of optimal warning strategies over time, and the use of warnings in real-life situations. This article also adds to the existing literature on optimal punishments for repeat offenders by identifying conditions under which escalating punishments are optimal.

Existing literature on law enforcement does not provide satisfying rationales for the use of warnings that are based on their informational value. This article highlights that such rationales emerge when one considers social costs associated with the punishment of uninformed individuals. One may be reluctant to incorporate such costs into law enforcement models on grounds that they appear to be ad hoc. But if people react to legal procedures (and, therefore, generate social costs) in a seemingly ad hoc manner, then incorporating such social costs might be the only way to capture the rationale behind why warnings and other puzzling methods are observed in the enforcement of laws.

49 See also Mungan (2012), reviewing the existing literature and pointing out that the assumption of fixed, rather than fluctuating, criminal tendencies may be responsible for the failure of many models to generate results that are consistent with our intuitions of justice. 


\section{Appendix}

Proof of Lemma 1: One can define the second period payoffs of informed individuals who have been detected and those who have not been detected in the first period, respectively, as follows:

$$
\Pi_{2}^{d}=\max \left\{b-p s_{2}, 0\right\} \quad \text { and } \quad \Pi_{2}^{n}=\max \left\{b-q p s_{1}, 0\right\}
$$

Hence, an informed individual's expected utility from committing crime in the first period is

$$
U^{C}=\left[b-q p s_{1}\right]+\left[p \Pi_{2}^{d}+(1-p) \Pi_{2}^{n}\right]
$$

and an informed individual's expected utility from not committing crime in the first period is

$$
U^{L}=\Pi_{2}^{n}
$$

Now let $\bar{\Sigma}=\max \left\{p s_{2}, q p s_{1}\right\}$ and $\underline{\Sigma}=\min \left\{p s_{2}, q p s_{1}\right\}$.

$b>\bar{\Sigma}$ implies that $\Pi_{2}^{d}>0$ and $\Pi_{2}^{n}>0$, therefore

$U^{L}=\Pi_{2}^{n}=\left[b-q p s_{1}\right]<\left[b-q p s_{1}\right]+\left[p \Pi_{2}^{d}+(1-p) \Pi_{2}^{n}\right]=U^{C}$ whenever $b>\bar{\Sigma}$

Hence, when $b>\bar{\Sigma}$ individuals will commit the crime in the first period. $b \leq \underline{\Sigma}$ implies that $\Pi_{2}^{d}=0, \Pi_{2}^{n}=0$ and $\left[b-q p s_{1}\right] \leq 0$, therefore

$$
U^{L}=\Pi_{2}^{n}=0 \geq\left[b-q p s_{1}\right]+\left[p \Pi_{2}^{d}+(1-p) \Pi_{2}^{n}\right]=U^{C} \text { whenever } b \leq \underline{\Sigma}
$$

Hence, when $b \leq \underline{\Sigma}$ individuals will not commit crime in the first period.

Now it is only necessary to check the behavior of informed individuals when $s_{1}$ and $s_{2}$ are chosen such that $\underline{\Sigma}<b \leq \bar{\Sigma}$.

In Case II, $\bar{\Sigma}=\underline{\Sigma}$, therefore we already have the requested result for this case, namely that individuals will commit crime only if $b>q p s_{1}=p s_{2}$.

In Case I, informed individuals with benefits such that $p s_{2}<b \leq q p s_{1}$ will commit crime in the second period only if they are caught in the first one. Hence, if the relation below holds, informed individuals will commit crime.

$$
U^{C}=\left[b-q p s_{1}\right]+\left[p\left(b-p s_{2}\right)\right]>0=U^{L}
$$

Therefore, informed individuals will commit crime in the first period if

$$
b>\frac{p}{1+p}\left[q s_{1}+p s_{2}\right]=b^{*}
$$

Note that $p s_{2}<b^{*} \leq q p s_{1}$. 
In Case III, individuals with benefits such that $q p s_{1}<b \leq p s_{2}$ will commit crime in the second period only if they are not caught in the first period. Hence, if the relation below holds, informed individuals will commit crime.

$$
U^{C}=\left[b-q p s_{1}\right]+\left[(1-p)\left(b-q p s_{1}\right)\right]>b-q p s_{1}=U^{L}
$$

Hence, individuals commit crime in the first period if $b>q p s_{1}$.

\section{Proof of Proposition 1:}

Part (iii): $S=0$ requires either $s_{1}=0, q=0$ or both. To prove the claim, it is sufficient to note that for any $q^{\prime}>0$, it follows that $I\left(q^{\prime}, 0\right)=q^{\prime}(2-p) p \alpha k>0=$ $I\left(0, s_{1}^{\prime}\right)$ for all $s_{1}^{\prime}$.

Parts (i) and (ii): Consider the following constrained minimization problem:

$$
\min _{q, s_{1}} I\left(q, s_{1}\right) \text { such that } S=p q s_{1}, s_{1} \geq 0 \text { and } 0<q \leq 1
$$

The solution to this problem describes the optimal policy variables to achieve a given level of expected sanctions for first-time offenders. An equivalent and more convenient formulation of the same problem, utilizing eq. (4), is

$$
\min _{q \in(0,1]} q(2-p) p \alpha\left[k+C\left(\frac{S}{p q}\right)\right] \equiv \min _{q \in(0,1]} \Omega(q, S)
$$

Differentiating $\Omega(q, S)$ with respect to q results in the following F.O.C.:

$$
\Omega_{q}(q, S)=(2-p) p \alpha\left[k+C\left(\frac{S}{p q}\right)-C^{\prime}\left(\frac{S}{p q}\right) \frac{S}{p q}\right]
$$

and the following S.O.C.:

$$
\Omega_{q q}(q, S)=(2-p) p \alpha C^{\prime \prime}\left(\frac{S}{p q}\right) \frac{S^{2}}{p^{2} q^{3}}>0
$$

Let $R(x) \equiv C(x)-x C^{\prime}(x)$. Since $C(0)=0, C^{\prime}>0$, and $C^{\prime \prime}>0$, it follows that $R(x)<0$ for all $x>0$ and $R^{\prime}=-x C^{\prime \prime}(x)<0$. Accordingly, when $\mathrm{S}$ is fixed at a particular value, $\mathrm{R}$ and $\Omega_{q}(q, S)$ are increasing in q. This implies that $\Omega_{q}(q, S)$ is maximized with respect to $q$ when $q=1$. Hence, if for a given $\mathrm{S}, \Omega_{q}(1, S)<0$, then $\Omega_{q}\left(q^{\prime}, S\right)<0$ for all $q^{\prime}$. And if there exists $\underline{S}$ such that $k=-R\left(\frac{S}{p}\right)$, then $\Omega_{q}(q, S)<0$ for all $S>\underline{S}$ regardless of the level of q. But such $\underline{S}$ exists since $C^{\prime \prime}\left(s_{1}\right) \geq a$, where a is a positive constant. To see this, note that $R^{\prime}=-x C^{\prime \prime}(x)<0$, hence $\lim _{x \rightarrow \infty} R^{\prime}(x)=-\infty$, therefore $\mathrm{R}$ is divergent. Hence, there exists $\underline{S}$ such that 
$k=-R\left(\frac{S}{\bar{p}}\right)$. Therefore, whenever $S \geq \underline{S}$, information costs are minimized when $q^{m}=1$, because, per the above observation, $\Omega_{q}(q, S)<0$ for all $S>\underline{S}$ and for all q.

For any $S^{\prime}$ such that $0<S^{\prime}<\underline{S}$, there exists a unique and positive $q^{m}<1$ which satisfies $k=-R\left(\frac{S^{\prime}}{p q^{m}}\right)$. To see this, first note that $-R\left(\frac{S^{\prime}}{p}\right)<-R\left(\frac{S}{\bar{p}}\right)=k$ where the inequality follows from the fact that $R^{\prime}<0$, and the equality follows from the definition of $\underline{S}$. Next, note that since R is divergent, there exists $q^{\prime}>0$ which is small enough such that $-R\left(\frac{S^{\prime}}{p q^{\prime}}\right)>k$. Combining these two results we have that $-R\left(\frac{S^{\prime}}{p}\right)<k<-R\left(\frac{S^{\prime}}{p q^{\prime}}\right)$. By utilizing the intermediate value theorem, and the fact that $R^{\prime}<0$, it follows that there exists a unique $q^{m}$ such that $0<q^{\prime}<q^{m}<1$ and $k=-R\left(\frac{S^{\prime}}{p q^{m}}\right)$. Hence, for any $S^{\prime}$ such that $0<S^{\prime}<\underline{S}$, there exists a unique and positive $q^{m}<1$ that minimizes information costs.

Proof of Proposition 2: Proposition 1 states that for all positive $S<\underline{S}$, there is a hybrid warning strategy that minimizes information costs. Hence, there is an interior solution to the minimization problem in eq. (20). Let $t\left(q^{m}, S\right)=(2-p)$ $p \alpha\left[k+C\left(\frac{S}{p q^{m}}\right)-C^{\prime}\left(\frac{S}{p q^{m}}\right) \frac{S}{p q^{m}}\right]$. Applying the implicit function theorem we have that:

$$
-\frac{t_{S}}{t_{q^{m}}}=\frac{q^{m}}{S}=\frac{d q^{m}}{d S}
$$

This is a simple first-order differential equation, whose solution is $q^{m}=c S$. Where $\mathrm{c}$ is the unknown slope, describing $q^{m}$ as a function of $\mathrm{S}$. But c must be such that $1=c \underline{S}$, since by definition $\Omega_{q}(1, \underline{S})=0$.

Proof of Proposition 3: It should first be noted that the choice of $s_{2}$ does not affect information costs. Keeping this in mind, the proof consists of four steps. (1) First, I will show that $p s_{2}=h$ gives uninformed individuals proper incentives. (2) Next, I will show that whenever $s_{1}$ is chosen such that $q p s_{1} \leq h$, it is welfare-maximizing to set $p s_{2}=h$. (3) Then, I will show that any punishment scheme where $q p s_{1}>h$ is sub-optimal. These observations together imply that optimal sanction pairs and warning strategies are such that $s_{1}^{*} \leq \frac{h}{q^{*} p}, s_{2}^{*}=\frac{h}{p}$. (4) Finally, I will show that given $s_{2}^{*}=\frac{h}{p}$, expected sanctions for first-time offenders $\left(q^{*} p s_{1}^{*}\right)$ must be set to balance information costs and benefits from deterrence, which requires under-deterrence.

(1) p proportion of uninformed individuals are either warned or sanctioned in the first period. These are transformed into informed individuals who face expected punishments of $p s_{2}$ in the event they commit crime in the second period. Hence, setting $p s_{2}=h$ gives them proper incentives. $(1-p)$ 
proportion of uninformed individuals remain uninformed, and the choice of $s_{2}$ does not influence their behavior.

(2) Whenever, $q p s_{1}=h$, it trivially follows that $s_{2}^{*}=\frac{h}{p}$ results in first-best deterrence and that there is no other $s_{2}$ that achieves the same result. Whenever $q p s_{1}<h$, by making use of Observation 2, and analyzing individuals' responses to various sanctions, one can show that statements (a)-(d) are true. The analysis showing how these statements follow is trivial and lengthy and is therefore omitted in this article, but is available from the author upon request.

(a) any sanction scheme where $p s_{2}<q p s_{1}$ is dominated by the sanctions scheme with $p s_{2}^{\prime}=q p s_{1}$.

(b) the sanction scheme where $p s_{2}=q p s_{1}$ is dominated by the sanction scheme with $p s_{2}^{\prime}=h$.

(c) any sanction scheme where $q p s_{1}<p s_{2}<h$ is dominated by the sanction scheme with $p s_{2}^{\prime}=h$.

(d) any sanction scheme where $q p s_{1}<h<p s_{2}$ is dominated by the sanction scheme with $p s_{2}^{\prime}=h$.

Observations (a)-(d) together imply that whenever $s_{1}$ and $q$ are chosen such that $q p s_{1} \leq h$, it is optimal to set $s_{2}=h / p$.

(3) It follows that any sanction pair such that $q p s_{1}>h$ is dominated by the sanction pair $s_{1}^{\prime}$ and $s_{2}^{\prime}$ satisfying $q p s_{1}^{\prime}=p s_{2}^{\prime}=h$, since the latter sanction pair results in first-best deterrence in both periods and less informational costs. Hence, any sanction pair where $q p s_{1}>h$ is sub-optimal.

(4) The above observations show that the optimal sanction pair is such that $s_{2}=\frac{h}{p}$ and $p q s_{1} \leq h$. Given this observation, and the results from Propositions 1 and 2, the claim can be proven as follows:

Let

$$
I^{*}(S)=\min _{q, s_{1}} \theta(q) \Psi\left(s_{1}\right) \quad \text { such that } S=p q s_{1}
$$

Then employing Observation 2 and the fact that $p s_{2}=h$, social welfare can be expressed as:

$$
\begin{aligned}
V(S)= & (1-\alpha)\left[2 \int_{h}^{\infty}(b-h) f(b) d b+(2-p) \int_{S}^{h}(b-h) f(b) d b\right] \\
& +\alpha\left[(2-p) \int_{0}^{\infty}(b-h) f(b) d b+p \int_{h}^{\infty}(b-h) f(b) d b\right]-I^{*}(S) \\
= & K+(2-p)(1-\alpha) \int_{S}^{h}(b-h) f(b) d b-I^{*}(S)
\end{aligned}
$$


where

$K=(1-\alpha) 2 \int_{h}^{\infty}(b-h) f(b) d b+\alpha\left[(2-p) \int_{0}^{\infty}(b-h) f(b) d b+p \int_{h}^{\infty}(b-h) f(b) d b\right]$

Differentiating $\mathrm{V}$ with respect to $\mathrm{S}$, we have $\mathrm{s}^{50}$

$$
V_{S}(S)=\left\{\begin{array}{ccc}
-(2-p)(1-\alpha)(S-h) f(S)-(2-p) p \alpha \frac{1}{\underline{S}}\left(k+C\left(\frac{S}{\bar{p}}\right)\right) & \text { if } & \underline{S} \geq S \geq 0 \\
-(2-p)(1-\alpha)(S-h) f(S)-(2-p) \alpha C^{\prime}\left(\frac{S}{p}\right) & \text { if } \quad S>\underline{S}
\end{array}\right.
$$

Note that this expression is negative when $S=h$ (regardless of whether $h>\underline{S}$ ). Hence, it follows that the $S$ maximizing this expression is such that $S<h$. In other words, $q^{*} p s_{1}^{*}<h$, which was the claim to be proven.

These observations together imply that the optimal sanction pair is such that $s_{1}^{*}<\frac{h}{q^{*} p}$ and $s_{2}^{*}=\frac{h}{p}$.

\section{Proof of Proposition 4:}

Part (i):

Small h: Since $\mathrm{V}$ is concave in $\mathrm{S}$, it is always decreasing if $V_{S}(0) \leq 0$. But $V_{S}(0)=(2-p)(1-\alpha) h f(0)-(2-p) \frac{p \alpha}{\underline{S}}\left(k+C\left(\frac{\underline{\underline{S}}}{p}\right)\right) \leq 0$ iff $h \leq \frac{\frac{\alpha p}{\underline{S}}\left(k+C\left(\frac{\underline{\underline{s}}}{\bar{p}}\right)\right)}{(1-\alpha) f(0)} \equiv h^{\prime}$.

Hence, for all $h \leq h^{\prime}, S=0$ maximizes V.

Large h:

$$
V_{S}(\underline{S}) \geq 0 \text { if } h^{\prime \prime} \equiv \underline{S}+\frac{\frac{\alpha p}{\underline{S}}\left(k+C\left(\frac{S}{\bar{p}}\right)\right)}{(1-\alpha) f(\underline{S})} \leq h
$$

Hence, for all $h \geq h^{\prime \prime}, S^{*}$, the maximizer of $\mathrm{V}$, is such that $S^{*}>\underline{S}$. Therefore, per eq. (26) $V_{S}(S)=0$ when $(1-\alpha)(h-S) f(S)=\alpha C^{\prime}\left(\frac{S}{p}\right)$, which is when $\mathrm{V}$ is maximized.

50 It should be noted that $V(S)$ is differentiable. To see this, evaluate both expressions for $V_{S}$ at $\underline{S}$ and verify that they are equal using the definition for $\underline{S}$. 
Intermediate h: When $h^{\prime}<h<h^{\prime \prime}$, it follows that $V_{S}(0)>0>V_{S}(\underline{S})$. Hence, V has a maximizer $S^{*}$, such that $\underline{S}>S^{*}>0$. Therefore, per eq. (26) $V_{S}(S)=0$ when $(1-\alpha)(h-S) f(S)=p \alpha \frac{1}{\underline{S}}\left(k+C\left(\frac{S}{p}\right)\right)$, which is when $\mathrm{V}$ is maximized.

Part (ii):

(1): Part (i) implies that $S^{*}=0$. In this case (per Proposition 1), the optimal warning strategy is $q^{*}=0$.

(3): Part (i) implies that $S^{*}>\underline{S}$. In this case (per Proposition 1), the optimal warning strategy is $q^{*}=1$.

(2): Part (i) implies that $0<S^{*}<\underline{S}$. In this case (per Proposition 1), the optimal warning strategy is hybrid. To see that $q^{*}$ is increasing in $h$, note that $\frac{d q^{*}}{d h}=\frac{1}{S} \frac{d S^{*}}{d h}=-\frac{1}{S}\left[\frac{V_{S h}}{V_{S S}}\right]=-\frac{1}{\underline{S}} \frac{(2-p)(1-\alpha) f(S)}{V_{S S}}>0$ since $\mathrm{V}$ is concave in S.

(4): Follows immediately from the expressions for $h^{\prime}$ and $h^{\prime \prime}$ in eqs (27) and (28).

Proof of Proposition 5: I will prove the claim by verifying the following four observations: Escalating penalties are optimal when (i) pure warning strategies are optimal $\left(q^{*}=0\right)$, (ii) no-warning strategies are optimal $\left(q^{*}=1\right)$, and (iii) when hybrid strategies are optimal $\left(0<q^{*}<1\right)$ and $h>\underline{S}$. But (iv) decreasing or uniform penalties are optimal when $h \leq \underline{S}$ and $0<q^{*}<1$.

(i) When pure warnings are optimal, the choice of $s_{1}$ is irrelevant (see Proposition 1 part (iii)); in other words, any $s_{1}$ is optimal. Therefore, it trivially follows that there are optimal escalating sanctions.

(ii) It follows from Proposition 3 that $s_{1}^{*} p q^{*}<h=s_{2}^{*} p$. But when no-warnings are optimal, it follows that $q^{*}=1$; hence $s_{1}^{*} p<h=s_{2}^{*} p$, which implies that $s_{1}^{*}<s_{2}^{*}$.

(iii) and (iv) When hybrid warning strategies are optimal, it follows that $s_{1}^{*}=\frac{S}{\bar{p}}$ (see Proposition 2) and that $s_{2}^{*}=\frac{h}{p}$ (see Proposition 3). Hence, $s_{1}^{*} \leq s_{2}^{*}$ iff $\underline{S} \leq h$.

Acknowledgments: I would like to thank two anonymous referees, Omri BenShahar, Giusseppe Dari-Mattiacci, Nuno Groupa, Bruce Kobayashi, Webster Ye, the participants of the American Law and Economics Association's 2011 Annual Meeting, the Canadian Law and Economics Association's 2010 Annual Meeting and the 27th Annual Meeting of the European Association of Law and Economics for comments, discussions, and suggestions, Kristan Rivers and Nick Horner for excellent research assistance, and the Amsterdam Center for Law and Economics for their support. The usual disclaimer applies. 


\section{References}

Becker, G. S. 1968. "Crime and Punishment: An Economic Approach,” 76 Journal of Political Economy 169-217.

Bentham, J. 1789. An Introduction to the Principles of Morals and Legislation. Oxford: Clarendon Press, First Published: 1789.

Burnovski, M., and Z. Safra. 1994. "Deterrence Effects of Sequential Punishment Policies: Should Repeat Offenders Be More Severely Punished?" 14 International Review of Law and Economics 341-350.

Chu, C. Y. C., S.-cheng Hu, and T.-yuan Huang. 2000. "Punishing Repeat Offenders More Severely," 20 International Review of Law and Economics 127-140.

Dana, D. A. 2001. "Rethinking the Puzzle of Escalating Penalties for Repeat Offenders," 110 The Yale Law Journal 733-783.

Emons, W. 2003. "A Note on the Optimal Punishment for Repeat Offenders," 23 International Review of Law and Economics 253-259.

Emons, W. 2004. "Subgame-Perfect Punishment for Repeat Offenders," 42 Economics Inquiry 496-502.

Emons, W. 2007. “Escalating Penalties for Repeat Offenders," 27 International Review of Law and Economics 170-178.

Folger, R., and M. A. Konovsky. 1989. "Effects of Procedural and Distributive Justice on Reactions to Pay Raise Decisions," 32 The Academy of Management Journal 115-130.

Friehe, T. 2009. "Escalating Penalties for Repeat Offenders: A Note on the Role of Information," 97 Journal of Economics 165-183.

Garoupa, N. 1997. "The Theory of Optimal Law Enforcement," 11 Journal of Economic Surveys 267-295.

Garoupa, N., and M. Rizzolli. 2012. "Wrongful Convictions Do Lower Deterrence," 168 Journal of Institutional and Theoretical Economics 224-231.

Harrington, W. 1988. "Enforcement Leverage When Penalties Are Restricted," 37 Journal of Public Economics 29-53.

Kaplow, L. 1990. "Optimal Deterrence, Uninformed Individuals, and Acquiring Information About Whether Acts Are Subject to Sanctions," 6 Journal of Law, Economics, \& Organization 93-128.

Konovsky, M. A., and R. Cropanzano. 1991. "The Perceived Fairness of Employee Drug Testing as a Predictor of Employee Attitudes and Job Performance," 76 Journal of Applied Psychology 698-707.

Lando, H. 2006. “Does Wrongful Conviction Lower Deterrence?” 35 Journal of Legal Studies 327-337.

Lando, H. 2009. "Prevention of Crime and the Optimal Standard of Proof in Criminal Law," 5 Review of Law and Economics 33-52.

Miceli, T. J. 1990. "Optimal Prosecution of Defendants Whose Guilt Is Uncertain," 6 Journal of Law, Economics, \& Organization 189-201.

Miceli, T. J., and C. Bucci. 2005. "A Simple Theory of Increasing Penalties for Repeat Offenders," 1 Review of Law and Economics 71-80.

Mungan, M. C. 2010. "Repeat Offenders: If They Learn, We Punish Them More Severely," 30 International Review of Law and Economics 173-177.

Mungan, M. C. 2011. "A Utilitarian Justification for Heightened Standards of Proof in Criminal Trials," 167 Journal of Institutional and Theoretical Economics 352-370. 
Mungan, M. C. 2012. "The Law and Economics of Fluctuating Criminal Tendencies and Incapacitation," 72 Maryland Law Review 156-218.

Nyborg, K., and K. Telle. 2004. "The Role of Warnings in Regulation: Keeping Control with Less Punishment," 88 Journal of Public Economics 2801-2816.

Png, I. P. L. 1986. "Optimal Subsidies and Damages in the Presence of Judicial Error," 6 International Review of Law and Economics 101-105.

Polinsky, A. M., and D. L. Rubinfeld. 1991. "A Model of Optimal Fines for Repeat Offenders," 46 Journal of Public Economics 291-306.

Polinsky, A. M., and S. Shavell. 1984. "The Optimal Use of Fines and Imprisonment," 24 Journal of Public Economics 89-99.

Polinsky, A. M., and S. Shavell. 1998. "On Offense History and the Theory of Deterrence," 18 International Review of Law and Economics 305-324.

Polinsky, A. M., and S. Shavell. 2000. "The Economic Theory of Public Enforcement of Law," 38 Journal of Economic Literature 45-76.

Polinsky, A. M., and S. Shavell. 2007. "Public Enforcement of Law," in A. M. Polinsky \& S. Shavell, eds. Handbook of Law and Economics 403-454. Amsterdam: North-Holland.

Posner, R. A. 1973. “An Economic Approach to Legal Procedure and ludicial Administration," 2 Journal of Legal Studies 399-458.

Rizzolli, M., and M. Saraceno. 2011. "Better That Ten Guilty Persons Escape: Punishment Costs Explain the Standard of Proof," 155 Public Choice 1-17.

Robinson, P. H., and J. M. Darley. 2003. "The Role of Deterrence in the Formulation of Criminal Law Rules: At Its Worst When Doing Its Best," 91 Georgetown Law Journal 949-1002.

Robinson, P. H., and J. M. Darley. 2004. "Does Criminal Law Deter? A Behavioral Science Investigation," 24 Oxford Journal of Legal Studies 173-205.

Rousseau, S. 2009. "The use of warnings in the presence of errors," 29 International Review of Law and Economics 191-201.

Seligson, M. A. 1980. "Trust, Efficacy and Modes of Political Participation: 손 Study of Costa Rican Peasants," 10 British Journal of Political Science 75-98.

Shavell, S. 1991. "Specific versus General Enforcement of Law," 99 Journal of Political Economy 1088-1108.

Shavell, S. 2007. "Optimal Discretion in the Application of Rules," 9 American Law and Economics Review 175-194.

Sherman, L. 1993. "Defiance, Deterrence, and Irrelevance: A Theory of the Criminal Sanction," 30 Journal of Research in Crime and Delinquency 445-473.

Stigler, G. J. 1970. "The Optimum Enforcement of Laws," 78 Journal of Political Economy 526-536.

Sunshine, J., and T. R. Tyler. 2003. "The Role of Procedural Justice and Legitimacy in Shaping Public Support for Policing," 37 Law and Society Review 513-548.

Tyler, T. R. 1990. Why Do People Obey the Law? New Haven, CT: Yale University Press.

Wesbrook, S. D. 1980. "Sociopolitical Alienation and Military Efficiency," 6 Armed Forces and Society 170-189.

Worchel, P., P. Hester, and P. Kopala. 1974. "Collective Protest and Legitimacy of Authority: Theory and Research," 18 Journal of Conflict Resolution 37-54. 
Copyright of Review of Law \& Economics is the property of De Gruyter and its content may not be copied or emailed to multiple sites or posted to a listserv without the copyright holder's express written permission. However, users may print, download, or email articles for individual use. 